Gazi University
Journal of Science
http://dergipark.gov.tr/gujs

\title{
GIS-based Services Analysis and Multi-Criteria for Optimal Planning of Location of a Police Station
}

\author{
Ranya Fadlalla ElSHEIKH ${ }^{1,2 *}$ \\ ${ }^{I}$ GIS Department, Faculty of Social Sciences, Jeddah University, Jeddah, Saudi Arabia \\ ${ }^{2}$ School of Survey, Faculty of Engineering, Sudan University of Science and Technology, Khartoum, Sudan
}

\author{
Highlights \\ - The selection of a location for a police station based on GIS. \\ - Combining service area analysis and multi-criteria analysis is proposed for the selection of a site. \\ - An optimal location was obtained by using a wide range of perspectives.
}

\section{Article Info}

Received: 20 Nov 2020

Accepted: 29 Nov 2021

\section{Keywords}

GIS

Service analysis

Police station

Site selection

Multi-criteria

\begin{abstract}
In sustainable urban planning, finding an optimal location for land use is critical to managing the distribution of land. Therefore, finding a location requires detailed information to conduct a correct evaluation of factors influencing the choice. The purpose of this paper is to find an appropriate site for a police station based on GIS in Alaziziyah Municipality, Jeddah. A novel method is proposed by combing service area analysis and multi-criteria analysis to reduce the emergency response time. The evaluation was conducted based on travel time from the two available police stations in the study area. The ten critical zones were generated by using network analysis with each zone representing one-minute travel time coverage. The critical zones were ranking, and weightage was applied as being crime risk-prone considering the distance from facilities and the travel time. The facilities were categorised into three groups, namely education, health, and tourism services. A suitability map was created to determine the priorities of alternative locations and the highly suitable area was overlaid with aerial photograph to determine land availability. The facility location-allocation was used to select the best location for setting up a police station. This approach revealed optimal solutions for government or planners as they seek to make the right decision for site selection.
\end{abstract}

\section{INTRODUCTION}

Choosing the optimal location for something new is a key factor in sustainable urban planning. Land use planning requires the integration of data from multiple sources and complex analysis to assess site selection [1]. The problem of site suitability assessment has often been tackled using Multi-Criteria Decision Analysis (MCDA) [2-4]. The literature regarding MCDA considers different methods and processes to resolve the decision-making problem in many fields such as mathematics, management, planning, and economics [5]. Finding the optimal location for a police station is influenced by different criteria such as distance from other police stations, distance from main roads, and nearness to crime-prone areas [6]. Visualisation of the spatial distribution of hot crime points and police stations can lead to identifying a suitable site for a new police station [7]. Nevertheless, many selections of emergency locations are undertaken by simple analysis in terms of measuring the geographical distribution of police station locations and determining the gab of the service area [6-8]. The ranking is a simple method, but it lacks a mathematical foundation [9]. To overcome this problem, Saaty (1980) proposed the pairwise compression method [10]. This method was developed in the context of the Analytic Hierarchy Process (AHP). The AHP has been employed in the GIS-based emergency site suitability procedures $[11,12]$. In the AHP method, every criterion under consideration is ranked in the order of individual judgment which to date has never been $100 \%$ accurate. In GIS-based buffer analysis, it is impossible to learn where a vehicle can reach in the required travel time. Integrating multiple disciplines such as service area analysis and multicriteria 
analysis results in finding a better solution since it uses a wide range of perspectives rather than a single approach and this increases the certainty of the study.

Finding a suitable place for a new police station required to meet different objectives such as reducing response time, minimising the total cost, and maximising coverage [13]. The powerful query, analysis, and integration mechanism of GIS make it an ideal scientific tool in handling a vast amount of spatial information [14]. Fast access to critical areas is essential during an emergency. Hence the proposed location should consider travel time as the main factor in evaluation. Utilising the capabilities of GIS in mapping the service areas based on travel time from the police stations requires the building of a network dataset by combining service area analysis and Multi-Criteria Analysis (MCA) to enhance decision making in the optimal planning of the location of a new police station.

\section{MATERIAL METHOD}

The method consists of two parts. In the first part, zones were created by using network analysis around existing police stations and each zone represented one-minute travel time coverage. Then, the facilities were determined as demand points in the critical zones and categorised into three groups as education, health and tourism services. In the second part, the ranking multi-criteria decision-making analysis method was used to site the risk-prone areas and produce a suitability map. The highly suitable area was overlayed with aerial photographs to determine land availability. Facility location-allocation was used to select the best location for setting up a new police station. Finally, the model and its characteristics were illustrated.

\subsection{Study Area}

Jeddah city is the second-largest city in Saudi Arabia. Jeddah's population is increasing dramatically due to out-migration to the city by individuals in search of jobs and better living [15]. With immigration and population keeping pace, the pressure on the police services has been tremendous. Jeddah province is divided into 14 municipalities with fifteen police stations. These municipalities are divided into districts such as Alaziziyah Municipality located on the western coast of the Kingdom of Saudi Arabia in Jeddah City, between latitudes $21^{\circ} 33^{\prime} \mathrm{N}$ and $21^{\circ} 30.33^{\prime} \mathrm{N}$ and Longitudes $39^{\circ} 13.5^{\prime} \mathrm{E}$ and $39^{\circ} 9^{\prime} \mathrm{E}$. The area was divided into five districts Alaziziyah, Alandulus, Alhamrah, Alrehab, and Mesherfah (Figure 1). It covers an area of $46 \mathrm{Km} 2$, while it has the highest population among other municipalities with a density of around $13.48 / \mathrm{km} 2$ [15]. Therefore, Alaziziyah municipality was selected as a study area and the analysis will be restricted to the extension of the study area and its networks. There are two existing police stations in the study area Northern and AL-Sharafia Police Station (Figure 2).

\subsection{Materials}

The road network was captured from satellite images (Google Earth) after geo-referencing by four control points collected from the Survey Authority in Jeddah. GPS was used to collect the coordinates of the existing police stations. The health, education, public services layers, and attributes data of the road networks were obtained from the General Department of Urban Planning in the Jeddah Municipality. Esri online imagery was used to determine the whereabouts of the undeveloped land. 


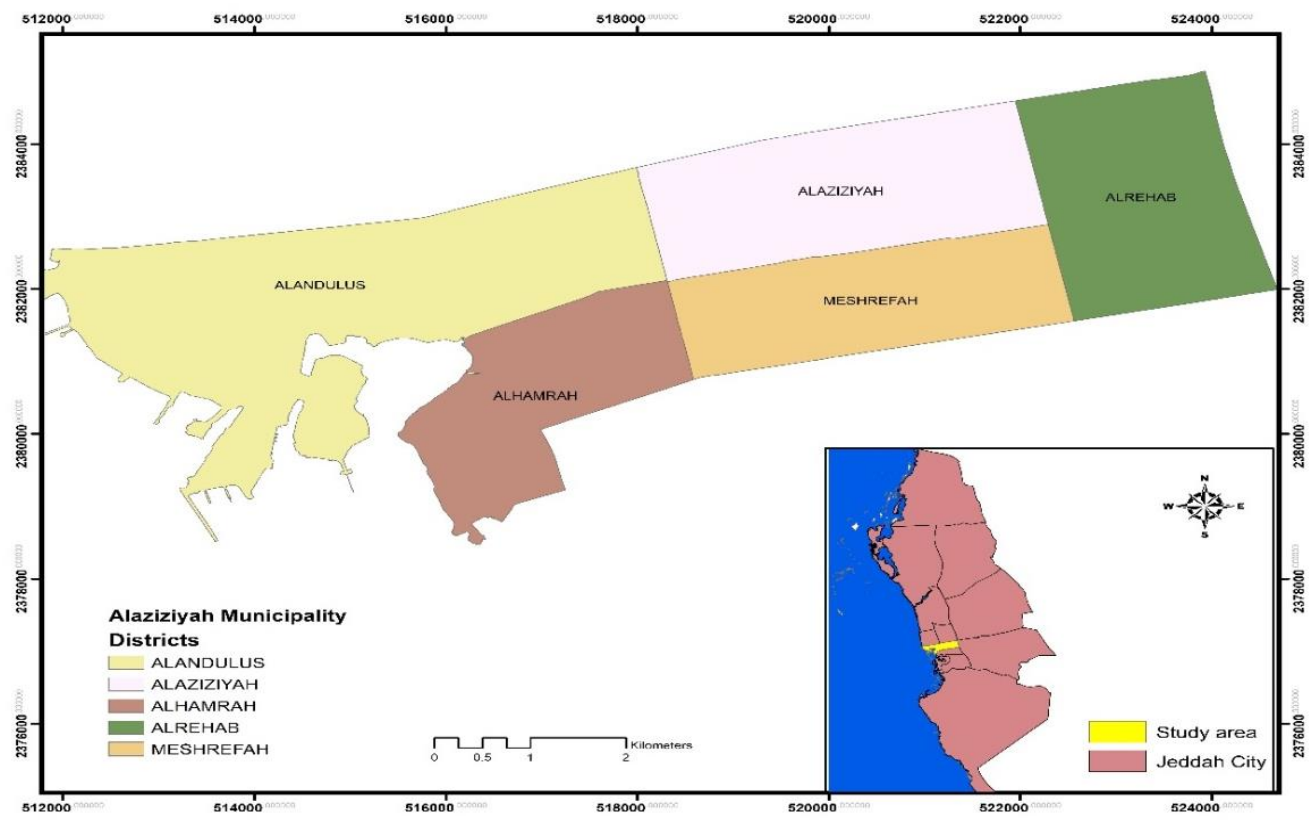

Figure 1. Al-Aziziyah Municipality

\subsection{Creating the Network}

Network analysis can powerfully model realistic network conditions. Network analysis can be used to analyse problems such as vehicle routing, closest facility, and service area, by giving the data of roadways and cost attributes [16-19]. In emergencies, fast access to the critical area is essential to save people's lives and improve damage mitigation. The time between the police service location and the incident can be measured in seconds. During an emergency, maps play a significant role in understanding the extent of the impact, response to the event as well as search and rescue [20]. Therefore, the first evaluation will be based on travel time based on network analysis. GIS can be used to calculate the access in terms of travel time and evaluate accessibility against certain criteria [21]. The Alaziziyah street network consists of more than twenty thousand secondary streets, thirty-two main streets, and two highways (Figure 2).

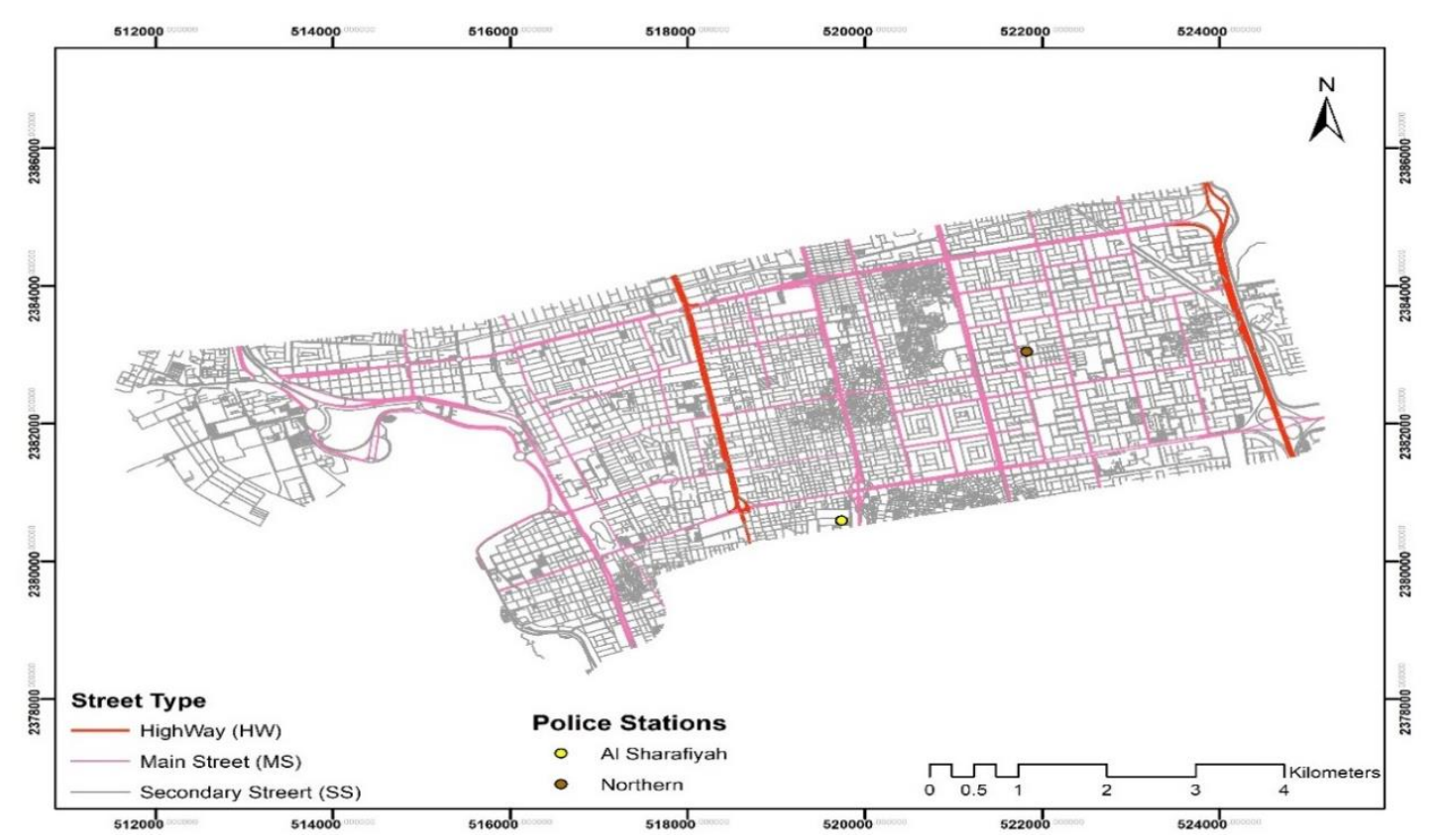

Figure 2. Al-Aziziyah Street Network 
In this paper, the network data set was created, and the attributes table included essential parameters such as (distance $(\mathrm{m})$, speed $(\mathrm{km} / \mathrm{h})$, road direction, road name, and type. An average speed of $40 \mathrm{~km} / \mathrm{h}$ has been set for secondary roads, $50 \mathrm{~km} / \mathrm{h}$ for main roads and $80 \mathrm{~km} / \mathrm{h}$ for motorways. Arrival time and return time were calculated based on speed and distance in minutes. Topology was performed to ensure model validation and connectivity relationships. Finally, the network dataset was created and the ten critical zones were created around the police stations. Each zone represented one-minute travel time coverage by using the service area application (Figure 3).

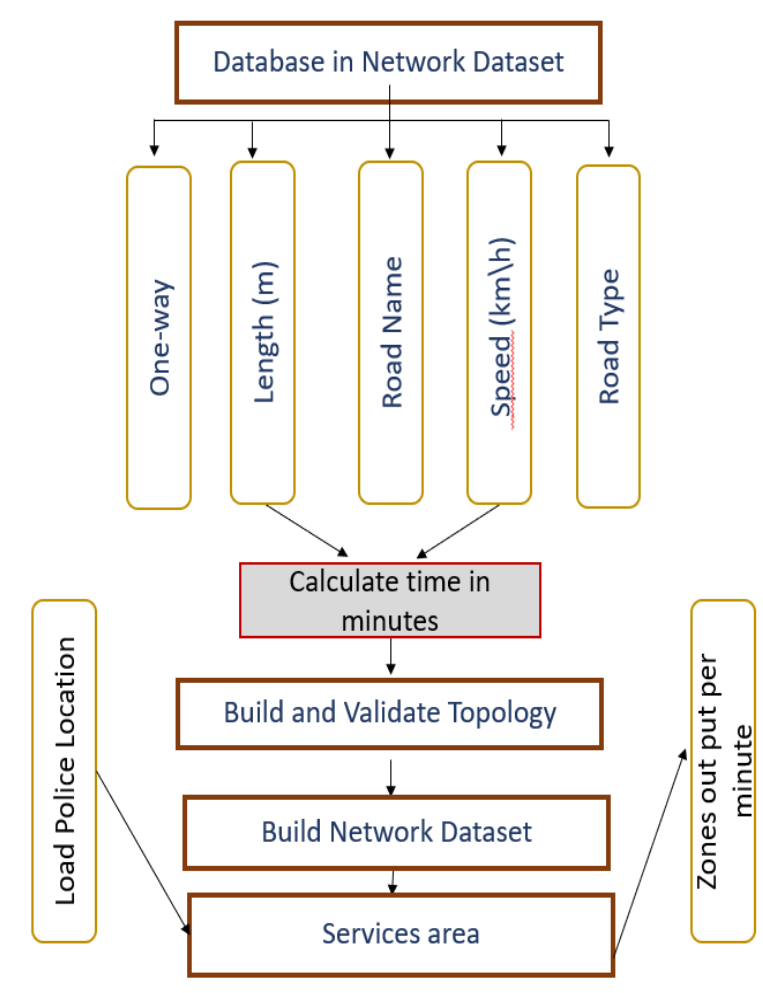

Figure 3. Network Analysis Workflow

\subsection{Multi-Criteria Analysis and Optimal Planning}

Public facility planning includes the allocation of facilities or services at optimal locations guided by different planning criteria. In MCDA the determination of the optimum land site for an area involves the integration of data from various sources. All these datasets can be considered as criteria. Every criterion will contribute towards the site suitability at different degrees called a weight [22]. The scope of the proposed location will be limited to the critical zone. The risk-prone areas were created based on travel time coverage and the distance from facilities. The ranking and weightage overlayed all maps to produce a single suitability map. The final suitability map was derived by multiplying each factor by its relative weight followed by the summation of the results. A highly suitable area was exposed on a layer and overlayed with Esri's online imagery for determining land availability. In the available lands, ten points were selected as candidate locations and the facilities were loaded as demand points. The location-allocation method was used to determine the best location. The chosen location was selected with the minimum travel time (Figure 4). 


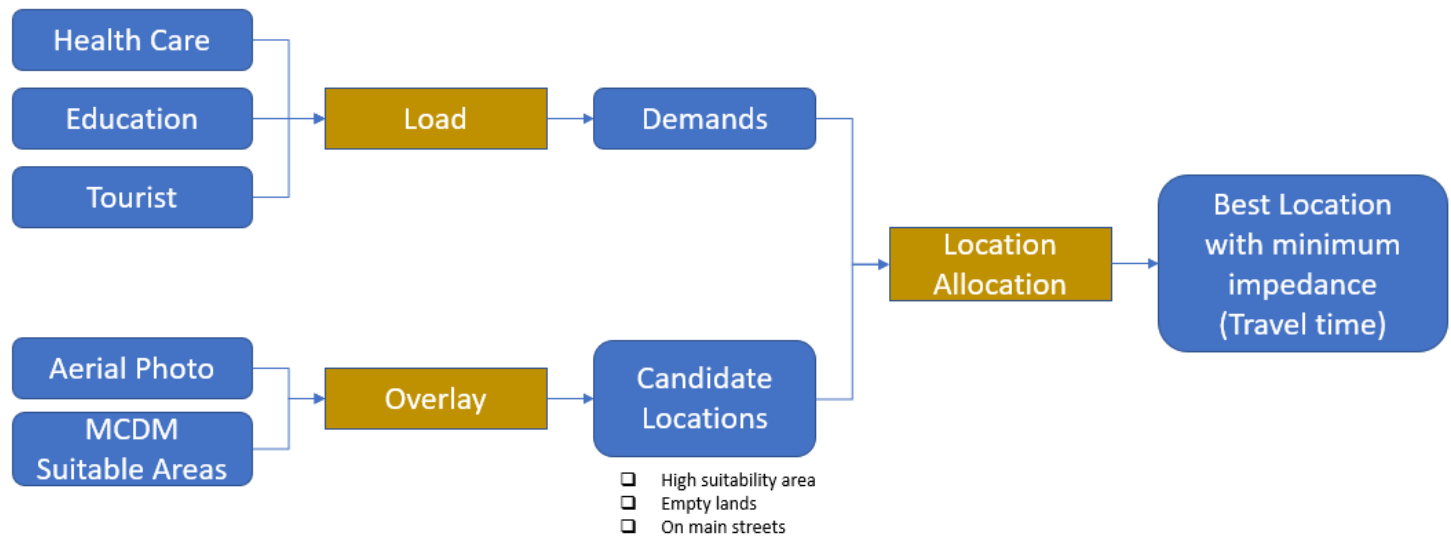

Figure 4. Location-Allocation Workflow

\section{RESULTS AND DISCUSSION}

In many of the previous studies, the service areas were produced by creating buffer zones from a particular point $[12,23]$. Accessibility always needs to be determined by travel time and road length [24]. Unlike the other studies Service Analysis was conducted based on four parameters. Firstly, time is a cost attribute chosen as impedance. Secondly, a one-way attribute is used to find solutions for vehicles that must obey one-way streets chosen as a restriction. Thirdly, a default break of 10 service areas and the extent of each one was calculated based on one minute from the police station. Finally, service areas were created by accumulating impedance in the direction away from or towards the police station (Figure 5).

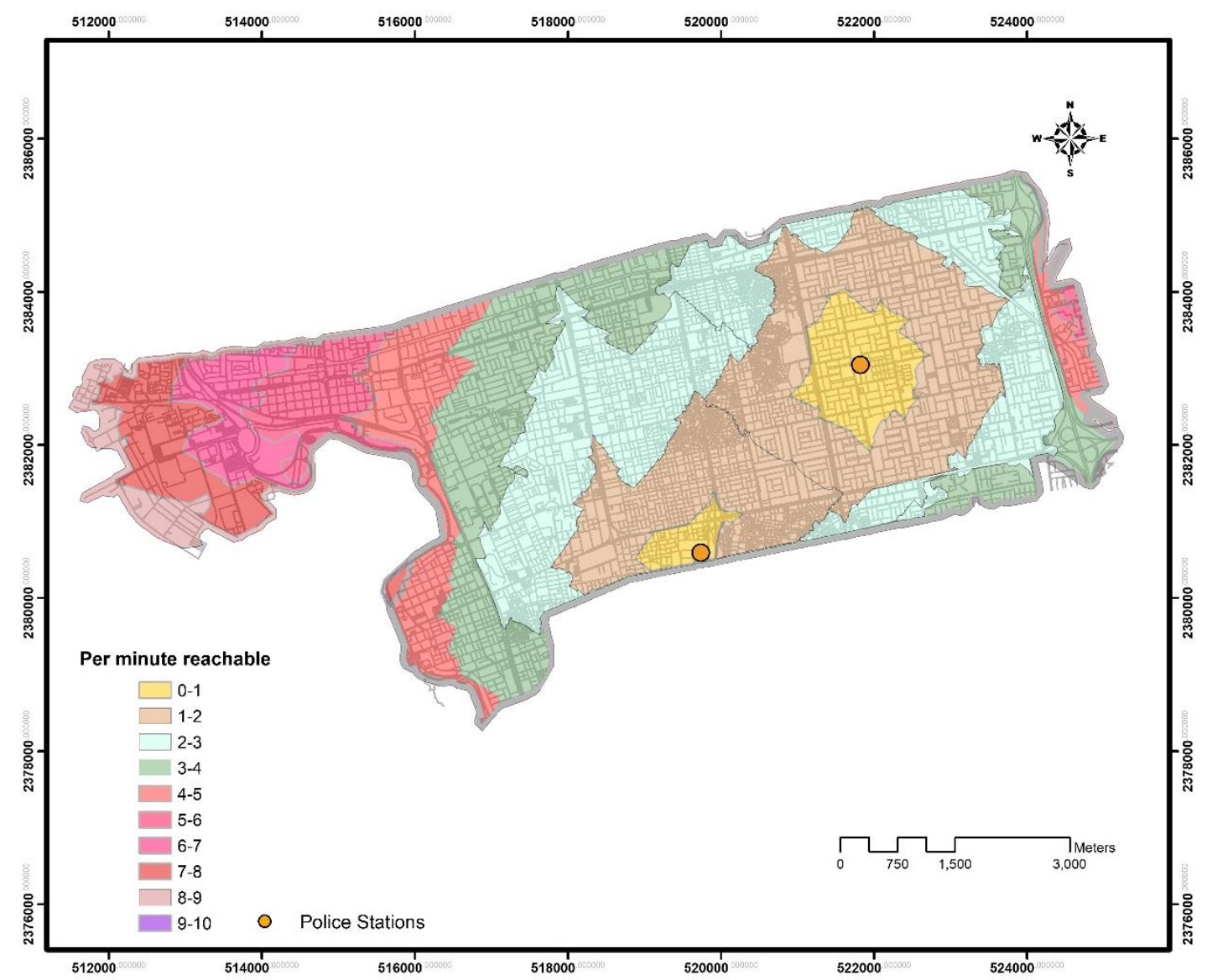

Figure 5. Service Area zones based on travel time from a police station 
The Service Area Analysis was based on time. These service areas show how accessibility varies with impedance. The emergency response time should be as low as possible and it depends on the condition of the emergency response vehicle and the possible obstructions along with the road network [25]. By arriving expeditiously, police officers can arrest any suspects and inquiring about the witnesses of the scene, along with averting the destruction or contamination of physical evidence [26]. Rapid response time (less than five minutes) is considered an effective tool used by police forces to detect crimes [27, 28]. Therefore, all zones were overlapped to evaluate the non-service area where 5 minutes of travel was considered not enough to reach a location. Such areas were considered as 'critical zones.

As stated in Table 1, up to 5 minutes of travel from the two police stations covered only about $64 \%$ of the total area. This revealed that the critical areas cover $46 \%$ of the study area and hence, it is required to have at least one more station for the non-served areas.

Table 1. Service Area zones and their areal coverage

\begin{tabular}{|l|l|l|l|l|}
\hline $\begin{array}{l}\text { Concentric } \\
\text { Zones }\end{array}$ & $\begin{array}{l}\text { Travel time } \\
\text { (Minutes) }\end{array}$ & $\begin{array}{l}\text { Zone } \\
\text { Covers } \\
\left(\mathrm{km}^{2}\right)\end{array}$ & $\begin{array}{l}\text { Cumulative } \\
\text { Coverage }\left(\mathrm{km}^{2}\right)\end{array}$ & $\begin{array}{l}\text { \% of the } \\
\text { area } \\
\text { covered by } \\
\text { the fire } \\
\text { service } \\
\text { stations }\end{array}$ \\
\hline 1 & 0 to 1 & 2.75 & 0 & 3 \\
\hline 2 & 1 to 2 & 12.05 & 14.8 & 15 \\
\hline 3 & 2 to 3 & 18.84 & 33.64 & 34 \\
\hline 4 & 3 to 4 & 16.75 & 50.39 & 52 \\
\hline 5 & 4 to 5 & 13.61 & 64 & 66 \\
\hline 6 & 5 to 6 & 10.97 & 74.97 & 77.5 \\
\hline 7 & 6 to 7 & 7.87 & 82.84 & 85 \\
\hline 8 & 7 to 8 & 5.31 & 88.15 & 90 \\
\hline 9 & 8 to 9 & 4.43 & 92.58 & 95 \\
\hline 10 & 9 to 10 & 3.07 & 95.65 & 98 \\
\hline
\end{tabular}

Land use planning is an effective tool for controlling and adjusting the distribution of land [29]. It involves measuring the needs of a proposed facility against the risk-prone nature of potential locations. Nowadays the hotspot trends of crime increase near a public area [30]. The facilities in critical zones were determined and classified into three classes, namely education, health, and tourism services as presented in (Figure 6).

In the ranking method, every criterion under consideration was ranked in the order of the preference of the decision maker. Inverse ranking was applied to these factors where 1 was the least important and 5 was the most important factor. The farthest areas from a particular facility received a low potential rank (1). The critical zones with 10-minute reachable time scored as the most important zones with a rank value of (5). After reclassifying and ranking all layers (Figure 7), a composite map showing the risk-prone area was created in 5 classes (Figure 8). Class 5 in a dark green colour was the highest prone-risk area and it was the most suitable site for the location of a new police station. 


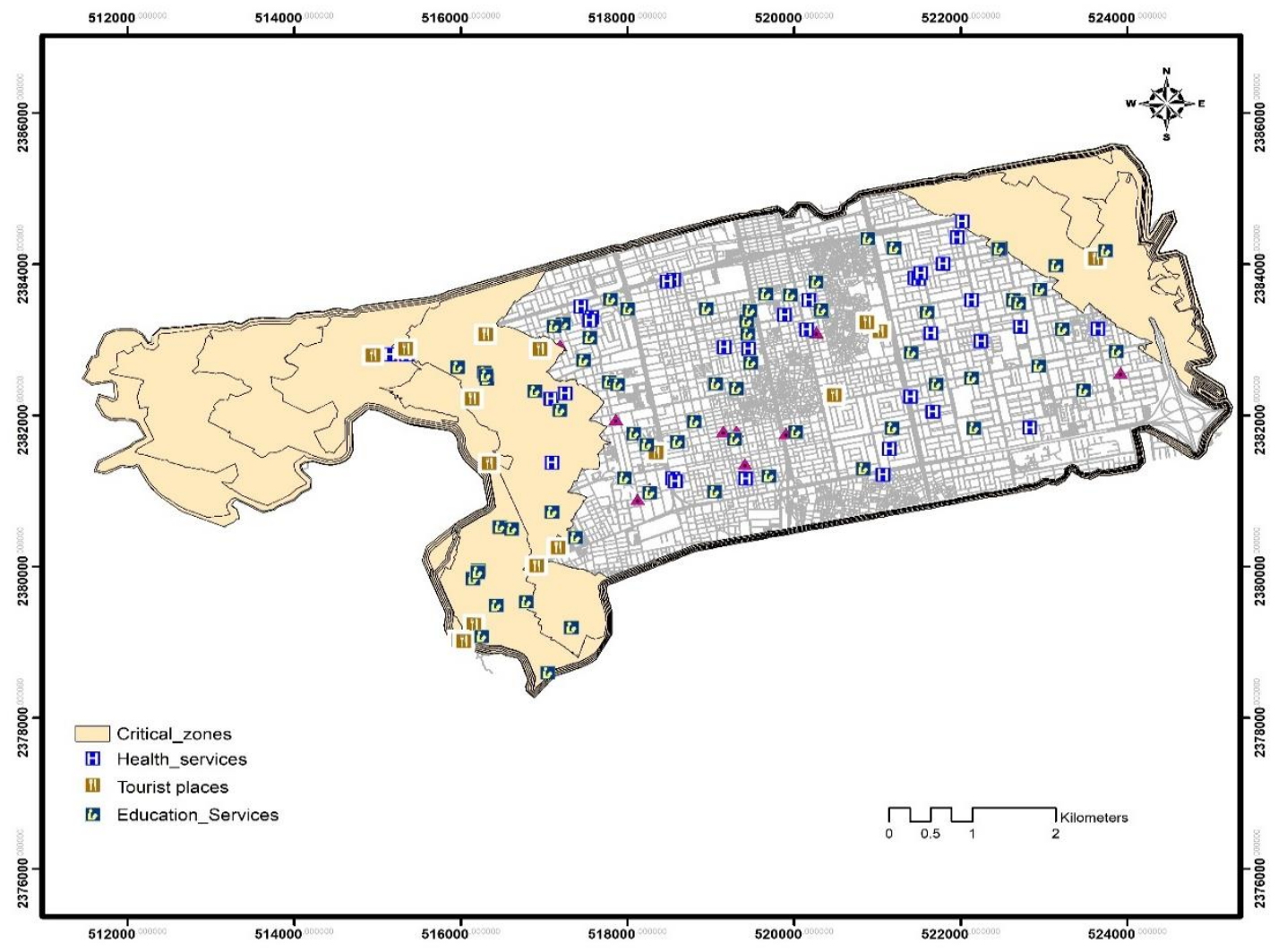

Figure 6. The facilities in the study area and critical zones
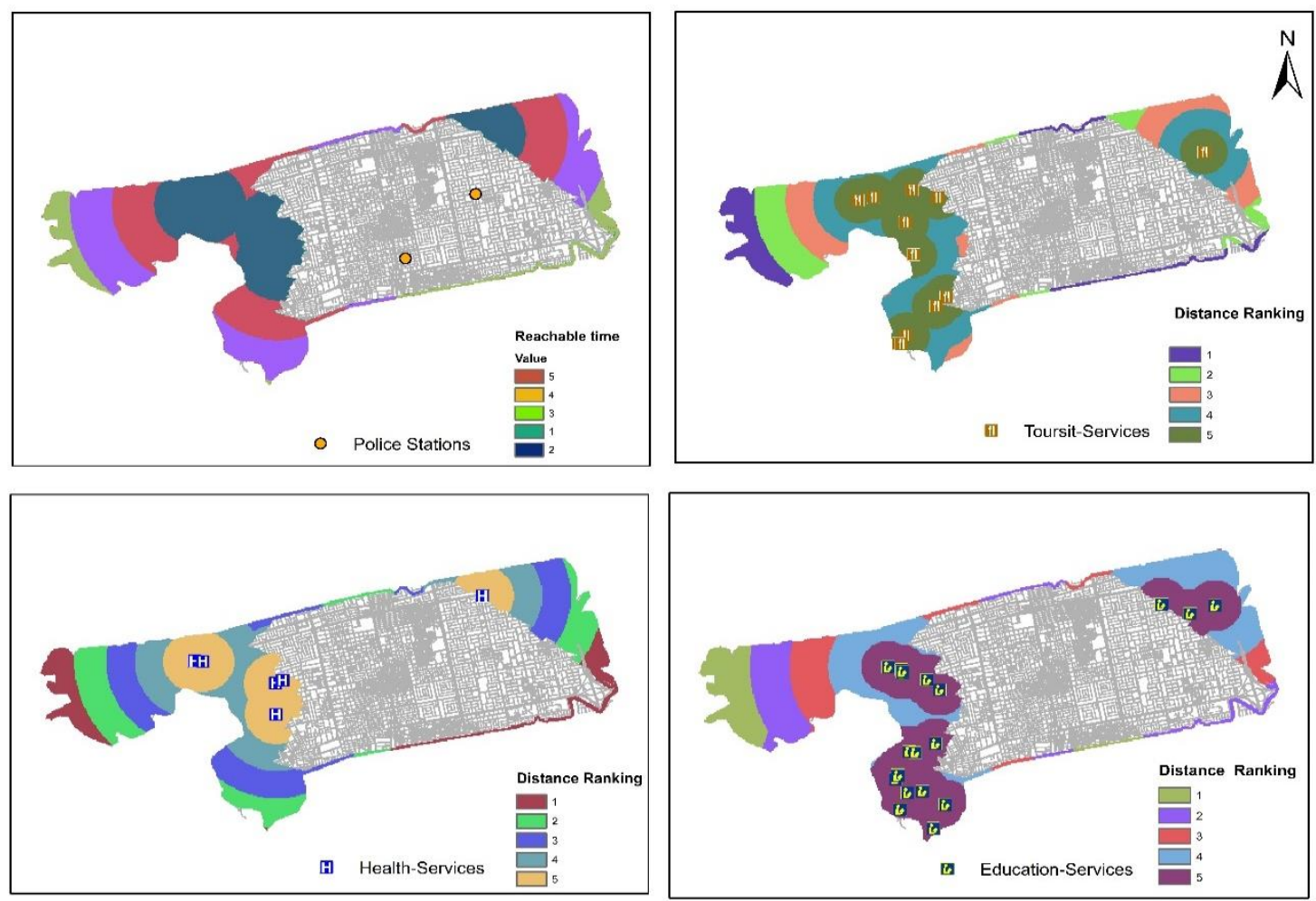

Figure 7. Multi-Criteria Analysis (Ranking layers) 


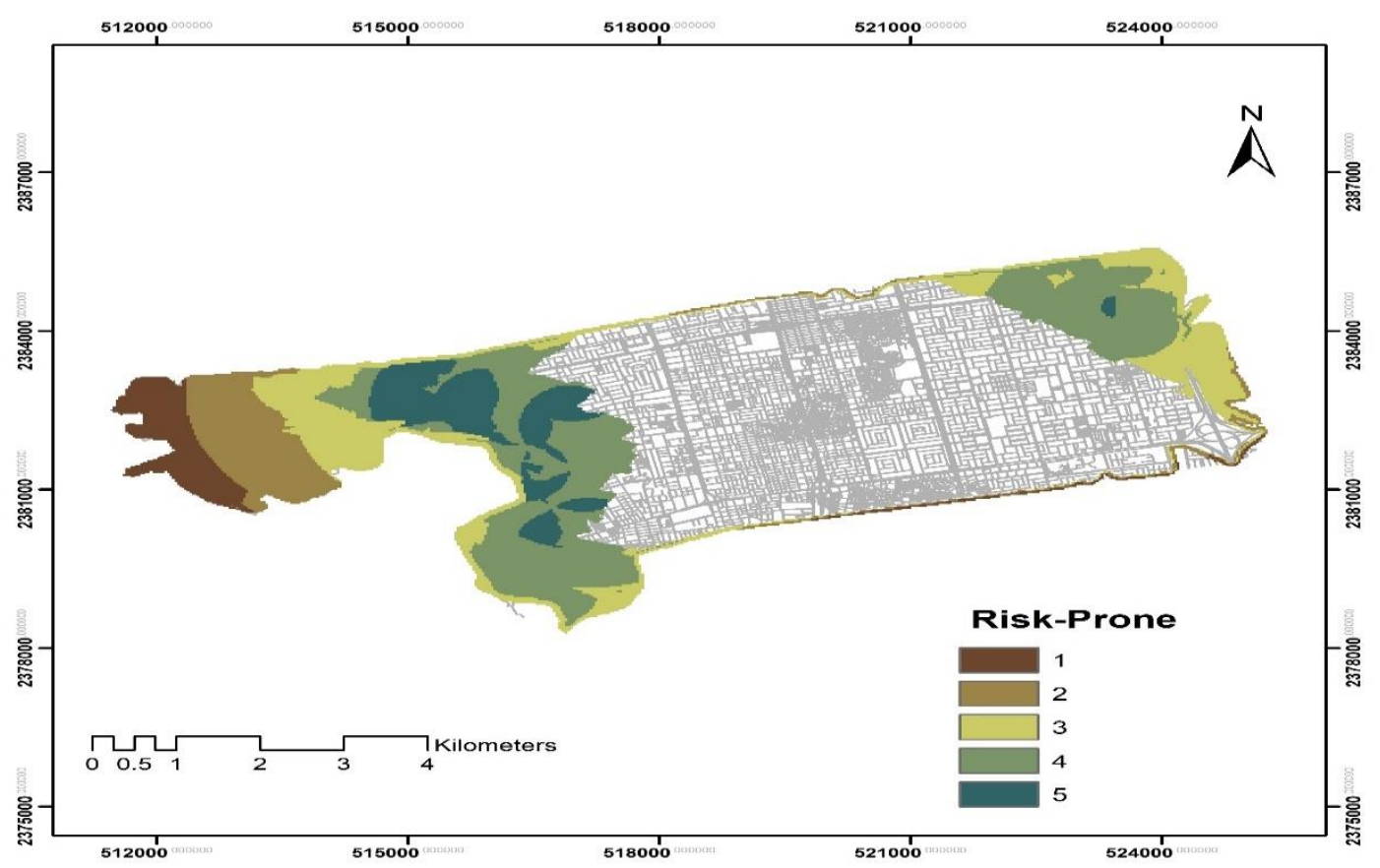

Figure 8. Risk-Prone areas

A suitability map was created to determine the priorities of alternative locations and the highly suitable area was overlayed with an aerial photograph to determine land availability. Subsequently, location-allocation analysis was used to select the best location for setting up a police station from the candidate locations. The suggested location (E: 517,216.759, N: 2,382,842.747) for a new police station was marked as a chosen location (Figure 9). It located in the intersection of Al Allaf street and Bugshan street in Alandulus District.

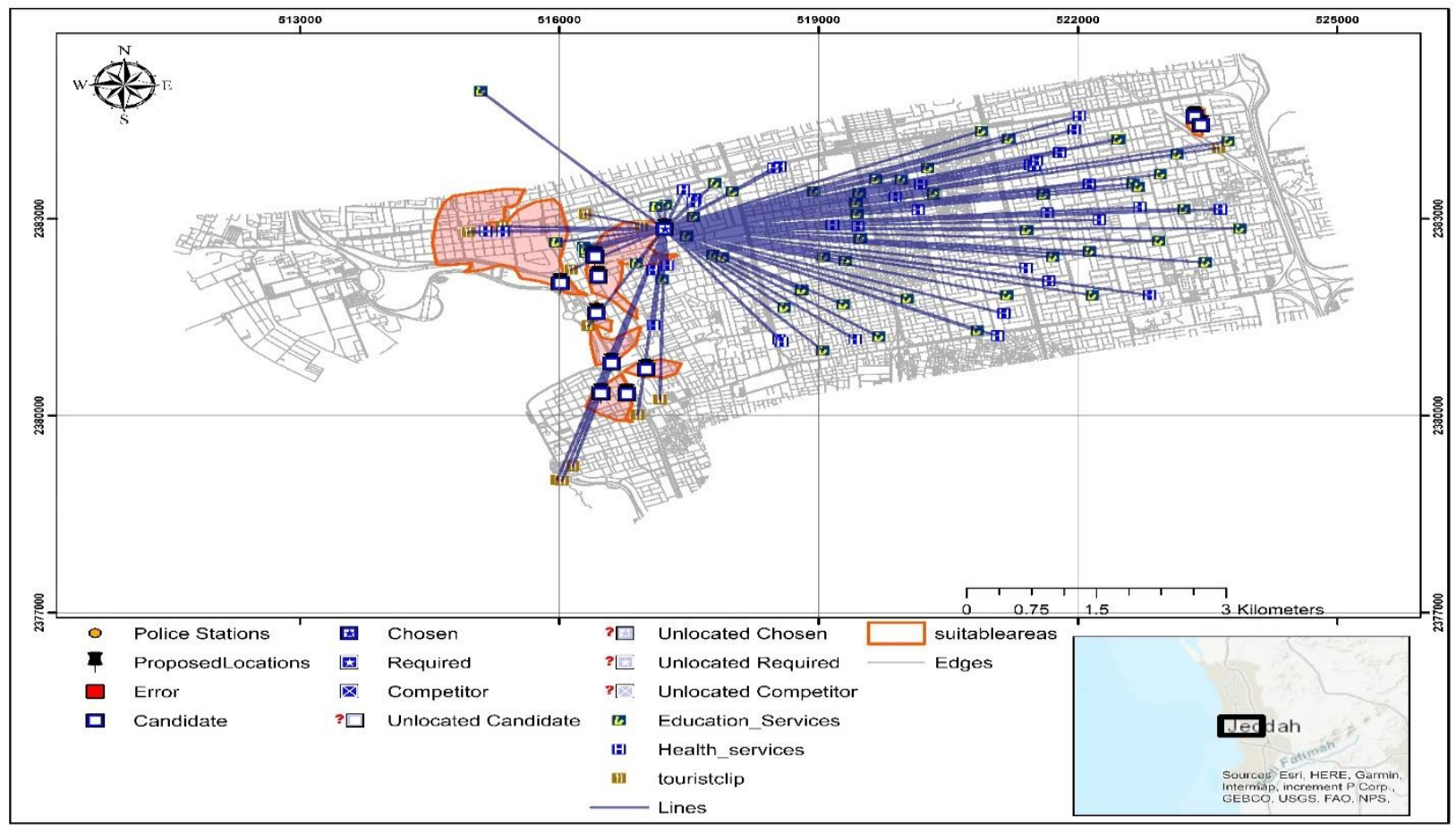

Figure 9. Finding the best location by Location-Allocation Analysis 


\section{CONCLUSION}

The Risk-prone map can give planners, insurers, and emergency services a valuable tool for site selection of a new police station. The study reviewed the role of GIS in decision-making and optimal planning, improved service delivery, increased safety by considering the travel time and distance from facilities and the hotspot trends of crime. The integration of service areas in network analysis and multi-criteria analysis provided a clear picture of high-risk zones where minimising response time would be necessary. The highrisk zones were considered as highly suitable areas for the candidate locations. Location-allocation analysis chose among the candidate facilities to find the best location that would minimise cost and maximise demand allocation. This approach revealed optimal solutions for government or planners as they sought to make the right decision for site selection.

For further studies, crime information and its spatial distribution should be considered as effective factors in site selection. Network Analysis was implemented for the Alaziziyah Municipality road network. The study area coverage could be extended to the whole city.

\section{CONFLICTS OF INTEREST}

No conflict of interest was declared by the author.

\section{REFERENCES}

[1] El Baroudy, A.A., "Mapping and evaluating land suitability using a GIS-based mod-el", Catena, 140: 96-104, (2016).

[2] Elsheikh, R.F.A., "Multi-criteria decision making in hotel site selection", International Journal of Engineering Science Invention, 6: 15-18, (2016).

[3] Neisani Samani, Z., Karimi, M., and Alesheikh, A.A., "A novel approach to site selection: Collaborative multi-criteria decision making through geo-social network (case study: Pub-lic Parking)", ISPRS International Journal of Geo-Information, 7(3): 82, (2018).

[4] Chakraborty, R., Ray, A., and Dan, P., "Multi criteria decision making methods for location selection of distribution centers", International Journal of Industrial Engineering Computations, 4(4): 491-504, (2013).

[5] Guarini, M.R., Battisti, F., and Chiovitti, A., "A methodology for the selection of multi-criteria decision analysis methods in real estate and land management process-es", Sustainability, 10(2): 507, (2018).

[6] Hasan Rahmani, M., and Golmehr, E., "The Ideal and Practical Pattern of Positioning Police Stations in Qazvin City and its Comparison with the Present Condition", European Online Journal of Natural and Social Sciences: Proceedings, 3(4): 320, (2015).

[7] Kim, Y., Lee, J., and Song, J., "Police Station Site Selection in Incheon using AHP, GIS", In Proceedings of the Korea Information Processing Society Conference, 1143-1145, Korea Information Processing Society, (2012).

[8] Ahmed, M., Muhammad, N., Mohammed, M.U., and Idris, Y., "A GIS-Based analysis of police stations distributions in kano metropolis", IOSR Journal of Computer Engineering, 8(4): 72-78, (2013).

[9] Liu, Y.S., Wang, J.Y., and Guo, L.Y., "GIS-Based Assessment of Land Suitability for Optimal Allocation in the Qinling Mountains, China", Pedosphere, 16(5): 579-586, (2006). 
[10] Saaty., T.L., "Decision making with the analytic hierarchy process", International Journal of Services Sciences, 1: 83-98, (2008).

[11] Erden, T., and Coskun, M.Z., "Multi-criteria site selection for fire services: the interaction with analytic hierarchy process and geographic information systems", Natural Hazards and Earth System Sciences, 10(10): 2127, (2010).

[12] Mirzahossein, H., Sedghi, M., Habibi, H.M., and Jalali, F., "Site selection methodology for emergency centers in Silk Road based on compatibility with Asian Highway network using the AHP and ArcGIS (case study: IR Iran)", Innovative Infrastructure Solutions, 5(3): 1-14, (2020).

[13] Şen, A., Önden, İ., Gökgöz, T., and Şen, C., "A GIS approach to fire station location selection", GeoInformation for Disaster Management Conference, (2011).

[14] Hamadouche, M.A., Mederbal, K., Kouri, L., and Anteur, D., "GIS-based multicriteria analysis: an approach to select priority areas for preservation in the Ahaggar National Park, Algeria", Arabian Journal of Geosciences, 7: 419-434, (2014).

[15] Jeddah-Municipality, Retrieved from https://www.jeddah.gov.sa/Municipalities/index.php, (2015).

[16] Ahmed, S., Ibrahim, R.F., and Hefny, H.A., "GIS-based network analysis for the roads network of the Greater Cairo area", Proceedings of 2nd International Conference on Applied Research in Computer Science and Engineering, (2017).

[17] Mar, S.S.H., and Ne, O.H., "GIS based Fire Emergency Response System for Mandalay", International Journal of Open Information Technologies, 7(12), (2019).

[18] Hetamsaria, P., "Applications of Network Analysis Features in GIS”, Platform: A Journal of Engineering, 3(2): 46-54, (2019).

[19] Elsheikh, R. F. A., Elhag, A., Sideeg, S. E. K., Mohammed, A. E., Gism, N. A., and Abd Allah, M. S., "Route network analysis in Khartoum city", Journal of Science and Technology, 17(1), (2016).

[20] Balasubramani, K., Gomathi, M., and Prasad, S., "GIS-Based Sevice Area Analysis for Optimal Planing Strategies: A Case Study of Fire Service Stations in Madurai City", Geographic Analysis, 5: 2319-5371, (2016).

[21] Comber, A., Brunsdon, C., Hardy, J., and Radburn, R., "Using a GIS-Based network analysis and optimisation routines to evaluate service provision: A case study of the UK post office", Applied Spatial Analysis and Policy, 2(1): 47-64, (2009).

[22] Prakash, T.N., "Land suitability analysis for agricultural crops: a fuzzy multicriteria decision making approach", ITC, (2003).

[23] Soltani, A., and Marandi, E.Z., "Hospital site selection using two-stage fuzzy multi-criteria decision-making process", Journal of Urban and Environmental Engineering, 5(1): 32-43, (2011).

[24] Flisek, P., and Lewandowicz, E., "A methodology for generating service areas that accounts for linear barriers", ISPRS International Journal of Geo-Information, 8(9): 423, (2019).

[25] Nicoară, P.S., and Haidu, I., "A GIS based network analysis for the identification of shortest route access to emergency medical facilities", Geographia Technica, 9(2): 60-67, (2014). 
[26] Vidal, J., Blanes I., and Tom, K., "The effect of police response time on crime detection", Retrieved from http://eprints.lse.ac.uk/64979/1/dp1376.pdf, (2015).

[27] Bratton, W., and Peter, K., "The turnaround: How America's top cop reversed the crime epidemic", Random House, (2009).

[28] Karn, J., "Policing and crime reduction:The evidence and its implications for practice", Washington DC: Police Foundation, (2013).

[29] Nguyen, L., Chou, T.Y., Fang, Y.M., and Lin, F.C., Van Hoang, T., and Huang, Y.M., "Optimal Site Selection for Land Use Planning: A Comparison Between Two Approaches of Fuzzy Analytic Hierarchy Process and Fuzzy Analytic Network Process", Proceedings of International Conference on Engineering and Natural Science, (2017).

[30] Yang, B., "GIS crime mapping to support evidence-based solutions provided by community-based organizations", Sustainability, 11(18): 4889, (2019). 